\title{
Design and analysis of FRP composite bolted joints for space structures
}

\author{
Dr. G. V. R. Seshagiri Rao ${ }^{a}$, K. $\operatorname{Naresh}^{\mathrm{b}}$ \& V. K. V. S. Krishnam Raju \\ ${ }^{a}$ Associate professor, Mechanical Engineering Department, Institute of Aeronautical Engineering, Dundigal, Hyderabad, India \\ ${ }^{b} \mathrm{M}$. Tech scholar, Mechanical Engineering Department, Institute of Aeronautical Engineering, Dundigal, Hyderabad, India \\ ${ }^{c}$ Associate professor, Mechanical Engineering Department, Institute of Aeronautical Engineering, Dundigal, Hyderabad, India
}

Article History: Received: 10 November 2020; Revised 12 January 2021 Accepted: 27 January 2021; Published online: 5 April 2021

\begin{abstract}
Man tries to learn his surroundings by showing tendencies such as discovering, researching, asking questions, and noticing the relationships between objects. In other words, he tends to understand the world he lives in with various judgments. Therefore, it is important to raise individuals with advanced reasoning skills, mathematical thinking skills, proofing skills, problem solving skills, metacognitive knowledge, skills or qualifications. It can be said that this can only be possible with the right teaching models, methods, techniques and teachers who can use them in the most efficient way. In this context, the aim of the study is; To determine the difficulties in the preparation process for LGS, which has been implemented in our country since 2018, and the reflections of LGS on mathematics education applied in schools within the framework of the opinions of mathematics teachers and make suggestions accordingly. In the study, the screening model was adopted because it was tried to portray the thoughts of a certain group of participants on a subject. The sample of the study; It consists of 110 mathematics teachers who attended 8th grade classes in the 2018-2019 academic year. The data obtained from teachers' opinions were analyzed by content analysis method. According to this; The predominant opinion is that students have problems in understanding, interpreting, thinking and reasoning in the new examination system, however, because the textbooks and the exam are not parallel, teachers have various difficulties. In this direction, various activities can be organized to increase students' motivation and to gain reading habit. In addition, it is thought that it would be beneficial to provide teachers with inservice training for the exam.
\end{abstract}

Keywords: Fiber-reinforced polymer; Carbon fiber strengthened plastics (GFRP); bolted joints.

\section{Introduction}

Fiber-reinforced plastic (FRP), is a composite materials generated by polymer matrix reinforced including fibers. Commonly used fibers are carbon, aramid or glass although other fibers, for example, asbestos or wood or paper have been in some cases utilize. The polymer is generally a vinyl ester, epoxy or polyester thermosetting plastic, and phenol formaldehyde resins are being utilized. Fiber-reinforced plastic are ordinarily utilize in the aviation, marine, automation and construction industries. Fiber strengthened plastic material were initially utilized in limited quantities in military airplanes during the 1960s, and within civil aviation starting 1970s. At the end of 1980s, polymer composites were being utilized by civil air plane industries for a variety of secondary wing and tail, (for example, wing trailing edge boards and rudder).Some of FRP composites utilized in space structures are as below.

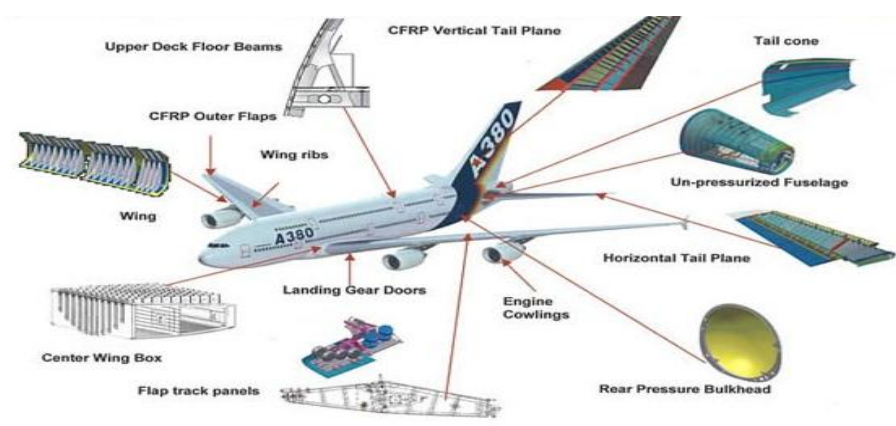

\subsection{Fiber as reinforcement and aluminum}

Carbon fiber strengthened plastics (CFRPs) - utilized initially in 1960s - ought their high structural efficiency to the extraordinary properties (lower thickness, high heat conductivity and mechanical properties at high temperatures) of the individual strands. Glass fiber strengthened plastics, boron fiber strengthened plastic, aramid 
fiber strengthened plastic (far superior to carbon fibers, yet multiple times more costly) these are also used, but seems carbon fibers have the best quality to cost ratio for primary load-carrying structure.

Glass fiber strengthened plastic (GFRP)- First developed in the mid 1930's generally called as fiberglass is a manufactured amalgamated material comprised plastic and incredibly fine filaments of glass. It is the biggest segment in the composites business. Glass fiber strengthened plastic composite materials is a cost efficient composite material when compared with Carbon fiber strengthened plastics and other metal fiber composites. From most recent couple of decade, this manufactured composite materials is demand after for its best quality, light weight, corrosion resistant. Glass fiber strengthened plastic products are in high demand in industries, for example, wind energy, aviation, and defence, automotive and construction industries etc for its lower weight and corrosion resistance properties.

Aluminum alloy, wrought, 6061 (Al, Mg, Si alloy) has wide acceptance in the manufacturing of light weight parts requiring a high strength/weight proportion, better corrosion resistant, less weight. Aluminum in its most pure form is excessively delicate and soft to be of structural use. However, its alloys, for example, 6061-T6 alloy, make it basically stronger and more helpful in manufacturing of products. 6061-T6 aluminum properties make it a material of decision for fabrication of Aerospace structures.

\section{Polymer matrices}

A remarkable efforts in developing composites is concentrated on advance in matrix polymers. A polymer with phenomenal properties is epoxy polymer is similar to those of many lighter weight, reinforced plastics and no losing of malleability, high compressive property- one of the most highest among fibers.

The FRP composites offer several features with respect to important requirements of aerospace structure as mentioned below:

- $\quad$ Less-weight because of high durability and rigidity.

- Corrosion resistant and Fatigue-resistant.

- Capacity to mould huge irregular shapes in small process time decreasing part count and assembly time.

- Capacity to maintain alignment and dimensional stability in space environments.

There are different types of plastics dominating in space structures: Carbon fiber strengthened plastics, Glass fiber strengthened plastic, Aramid fiber strengthened plastic or Basalt Glass fiber strengthened plastic fibres.

Table 1. Properties of different fibres explained in below

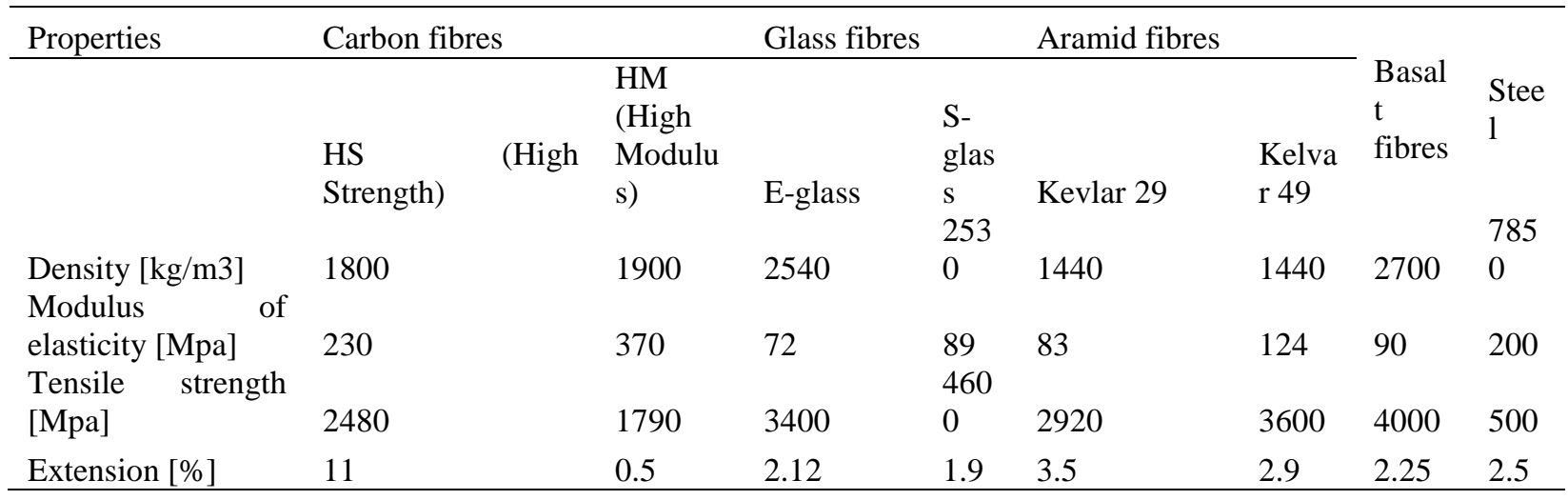

As indicated by NAS (national aerospace standards) high strength bolts are available, which are broadly utilized in fastening the aerospace structural joints. Aircraft quality bolts are produced using aluminum alloys, titanium, alloy steel and stainless steel. The standard bolts utilized in aircraft construction are AN3 through AN20.

\section{Modelling}

Modeling of FRP composite bolted joint is done by following the above designing principles. Here the dimension of the work piece material is taken as 200x72x6 in mm. The bolt, nut and work piece are modelled separately in part designing. The two parts are then assembled in the assembly design using the contact constraints. 


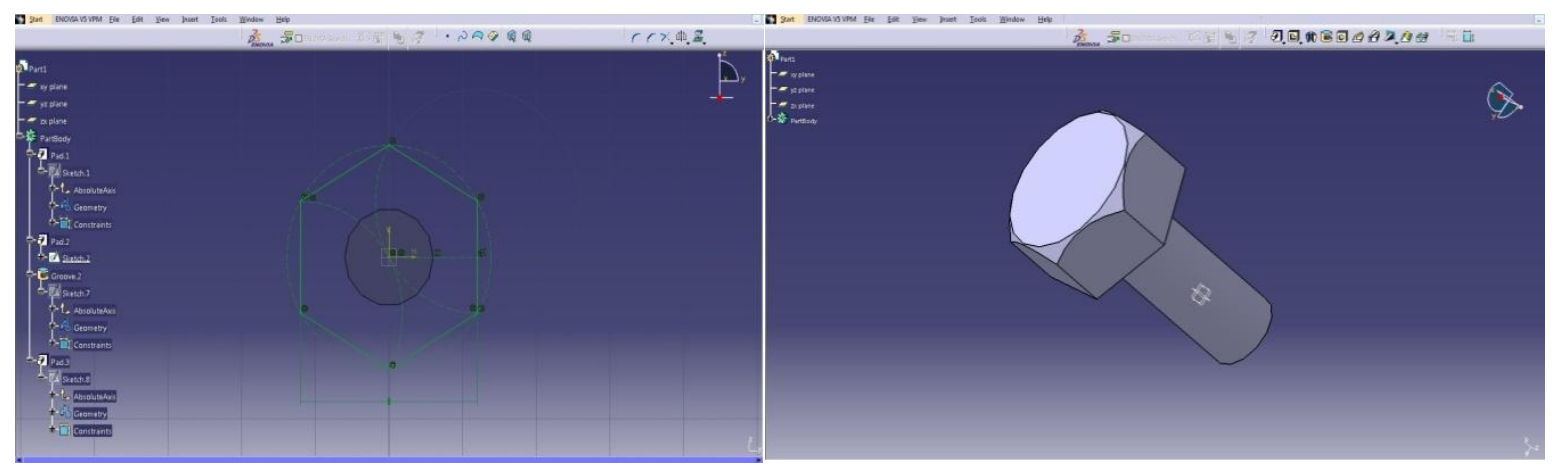

Fig 2: 2D diagram of M12 bolt

Fig 3: 3D model of the M12 bolt

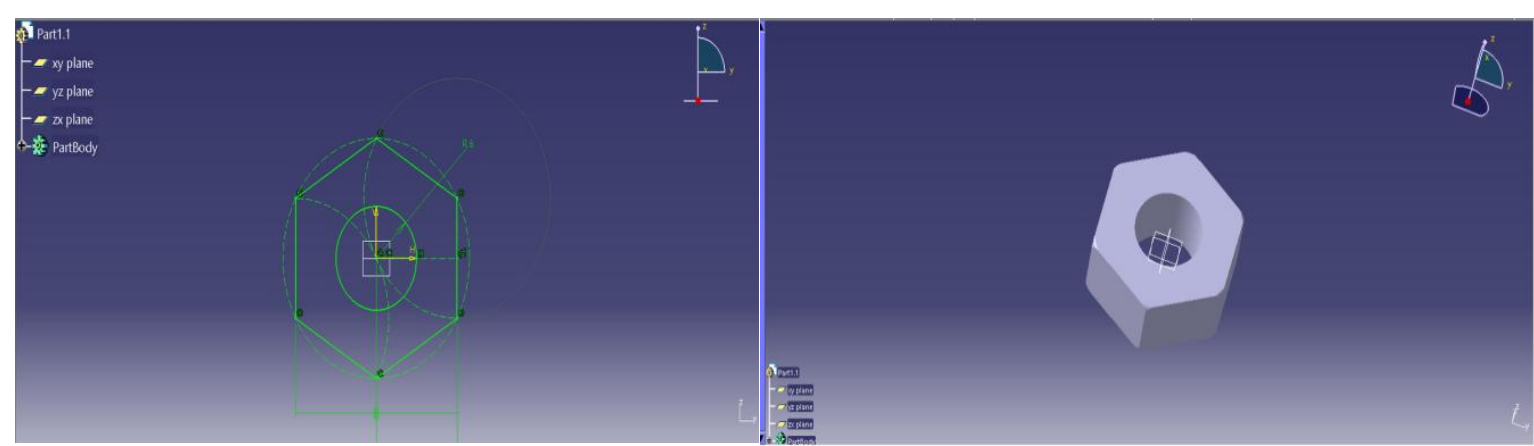

Fig4: 2D sketch of the Nut

Fig 5: 3D model of the Nut.

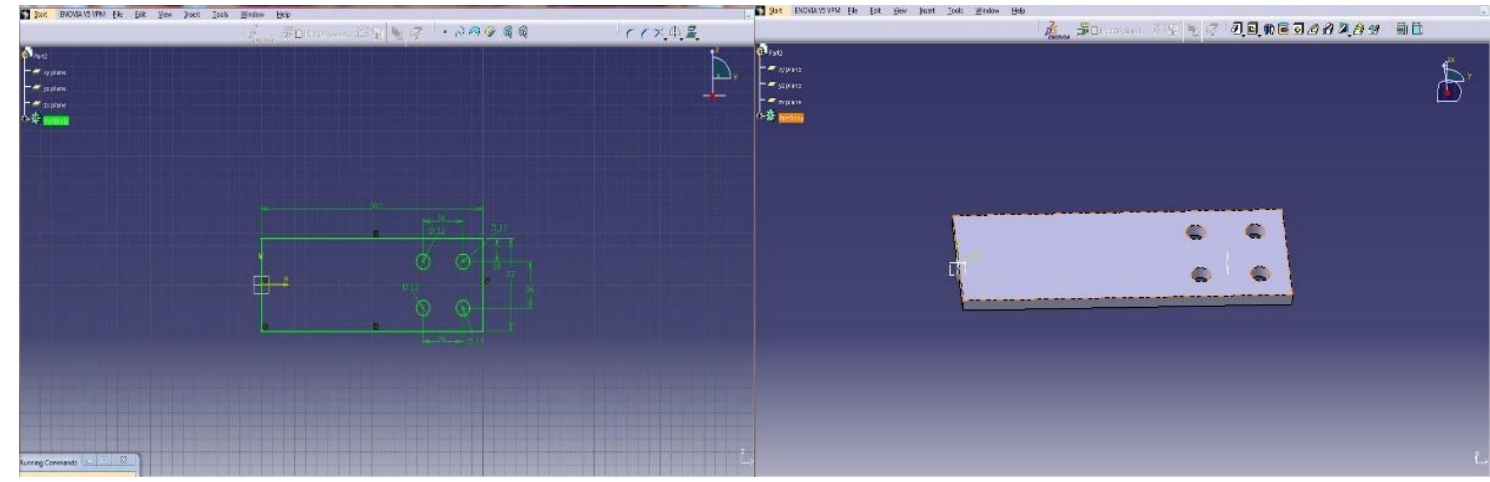

Fig6: 2D sketch of the plate

Fig 7: 3D model of the plate.

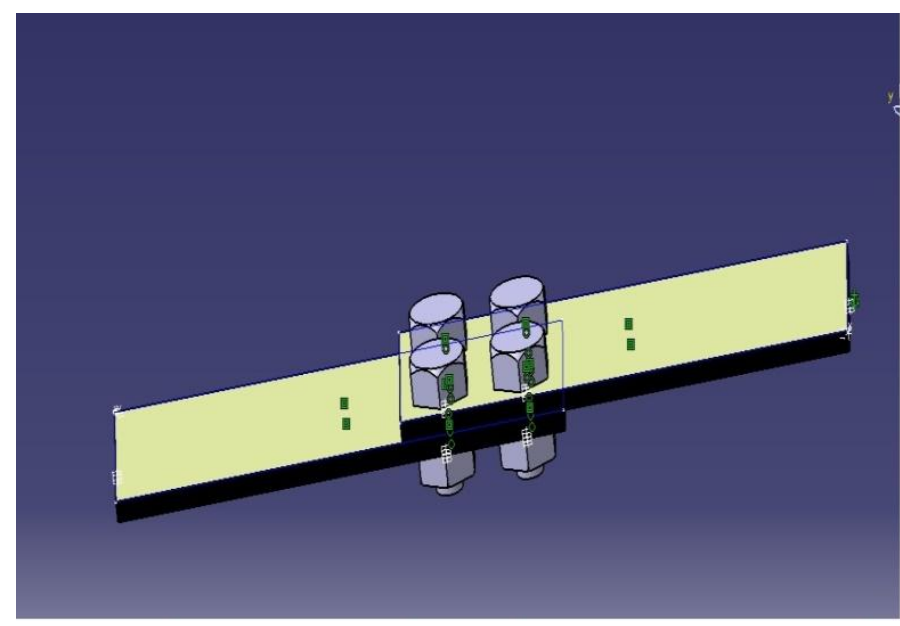

Fig 8: Model of double bolted lap joint 


\section{Analysis}

In this section there are five major areas where the analysing of the process is done using the simulation software ANSYS workbench 14.5 they are:

- Engineering information

- Geometry

- $\quad$ Meshing

- $\quad$ Setup

- Solution

- $\quad$ Results

\subsection{Engineering information}

In engineering informationstep the properties of the different materials which are used in the experiment are selected and added to each of them.

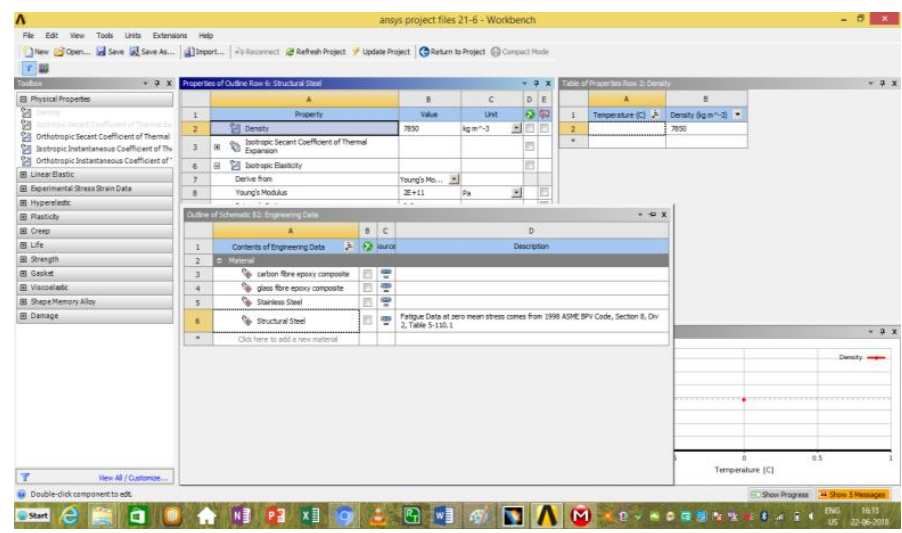

Fig 9: Engineering data

\subsection{Geometry}

Here in this section the geometry is normally created in the design modeller of the ANSYS work bench if only the geometries are small and simple, If the geometries or assembly parts are complex then the parts are designed in the modelling software's which serve better purpose in modelling. Here the geometry part can be imported from the system which has been modelled in the modelling software.

\subsection{Meshing}

This is one of the important part of the analysis as the nodes and elements are applied in this section depending upon the size, shape and the contact between the geometries.

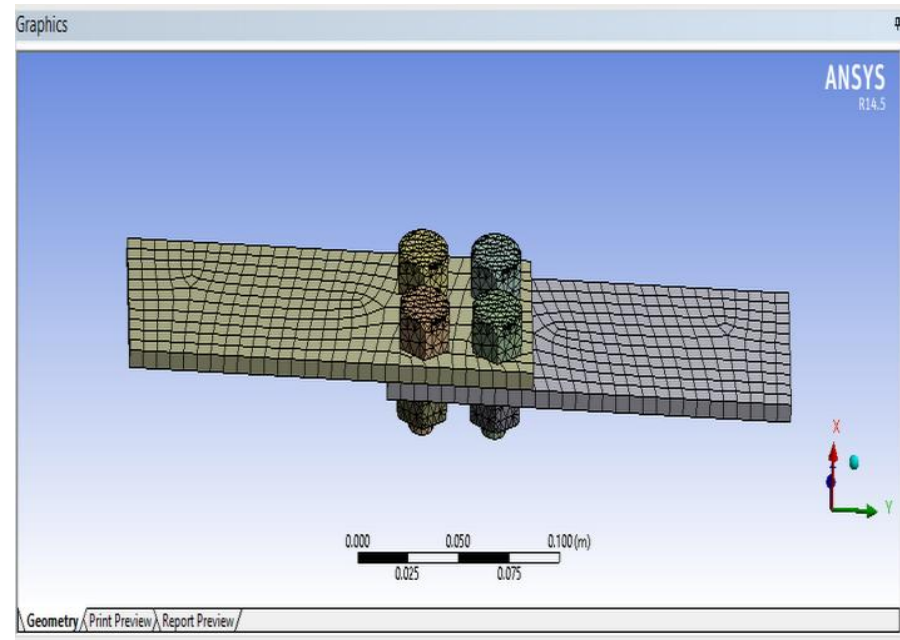

Fig 10: Meshing 


\subsection{Static structural}

In this structural examination determine the forces, stress, strains and displacement in structure or parts induced by load that don't cause significant inertia and damping effect. Response condition steady loading are consider; that is the loads and the structure reaction are expected to fluctuate gradually with respect to time. A static structural load can be executed utilizing the ANSYS. The type of loading that can be applied in static analysis include:

- Externally induced pressures along with forces

- $\quad$ Steady-state inertial force, (for example, gravity or rotational speed)

- $\quad$ Induced (nonzero) displacement

- $\quad$ Temperature (for heat strain)

In this section static analysis is examined for two different FRP composite materials i.e, CFRP and GFRP and the nut, bolt material same as stainless steel in both the aspect. The force is to be developed on the FRP material plate. The joined plate is arrested in opposite direction to the power applied utilizing the fixed supports to the plate.

The force is given as $2 \mathrm{kN}$ and the direction is allocated in y direction. All the parameters are applied on the plate and the experiment is solved by clicking the solve option.

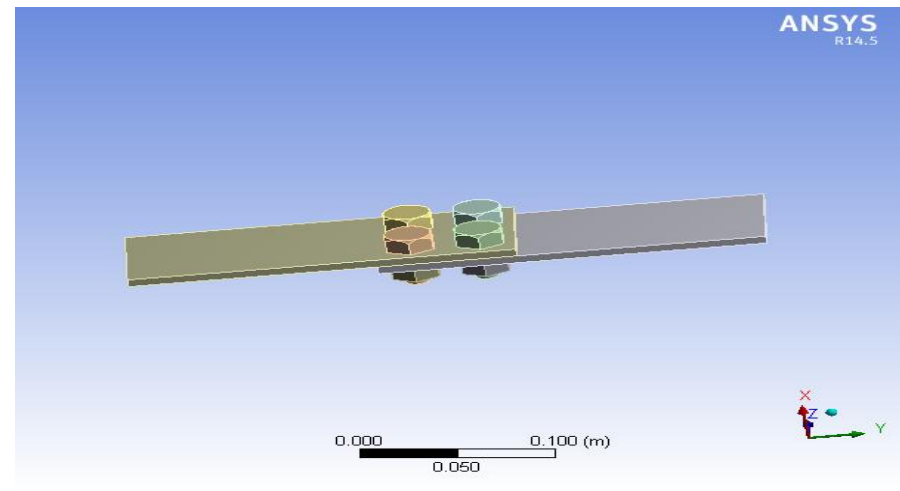

Fig 11: Geometric data

\subsection{Experimental values}

In this experiment the input values given to the simulation software. The initial conditions are the tensile force applied on the plate and the frictional contacts are mentioned with minimum frictional coefficient value. The value of the force is $2 \mathrm{kN}$. The young's modulus value for different materials is provided. These are the initial condition values for the experiment. The experiment is conducted for two different composite materials.

\subsection{Results}

The maximum total deformation $0.8542 \mathrm{~mm}$ is observed at the end where force is applied and the minimum force is observed at fixed end. The below figs shows the stress analysis results of CFRP composite bolted joint using ANSYS software.

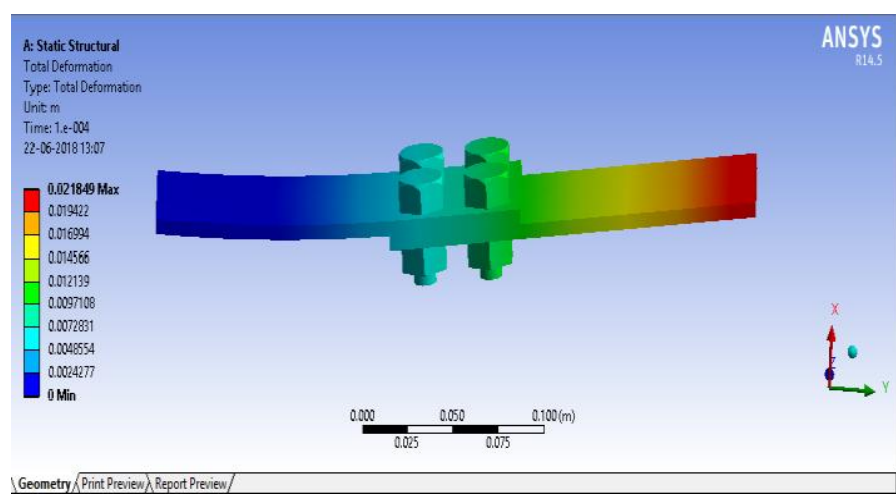

Fig 12: Total deformation of CFRP composite bolted joint. 


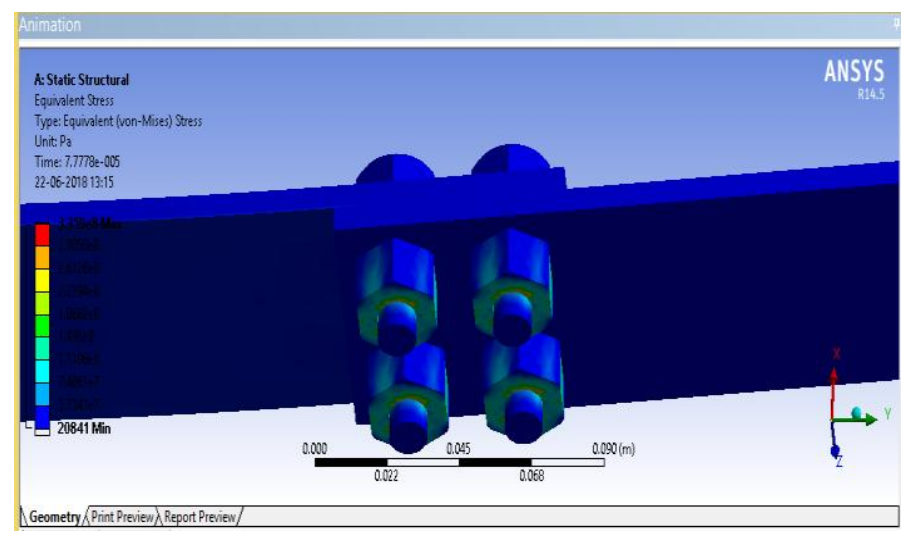

Fig 13: Von mises stress of CFRP composite bolted joint.

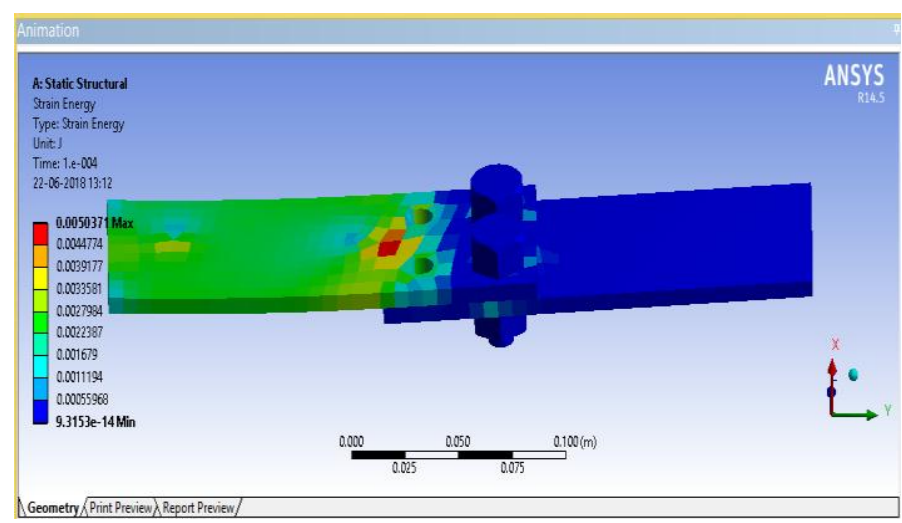

Fig 14: Strain energy of CFRP composite bolted joint

\subsubsection{Stress analysis of GFRP composite bolted joint}

The maximum total deformation $3.6782 \mathrm{e}-004 \mathrm{~m}$ is observed at the end where force is applied and the minimum force is observed at fixed end. The below figs shows the stress analysis results of GFRP composite bolted joint using ANSYS software.

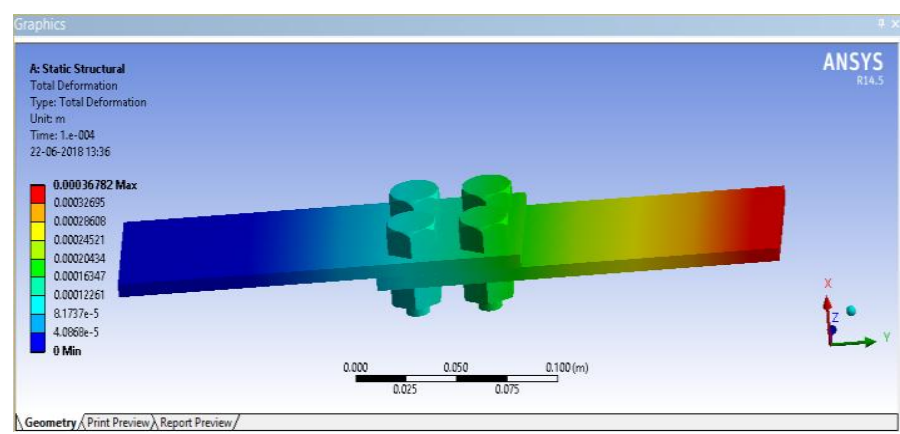

Fig 15: Total deformation of GFRP composite bolted joint. 


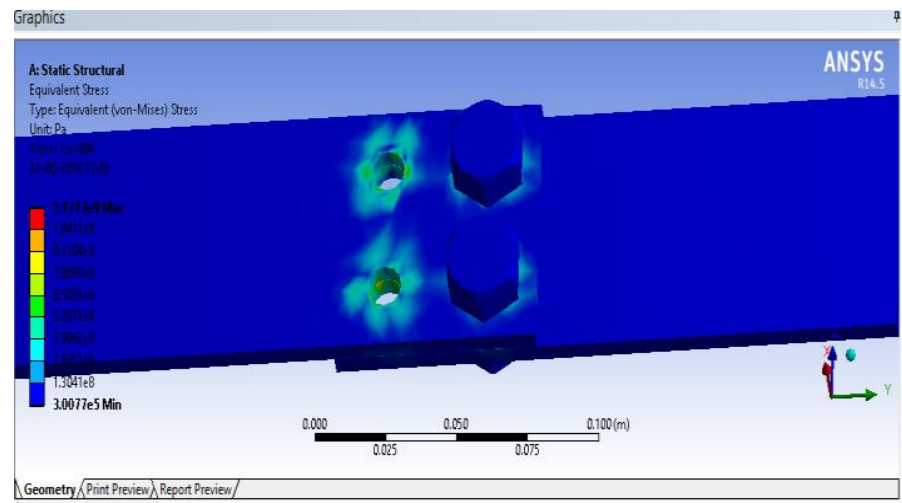

Fig 16: Von mises stress of GFRP composite bolted joint

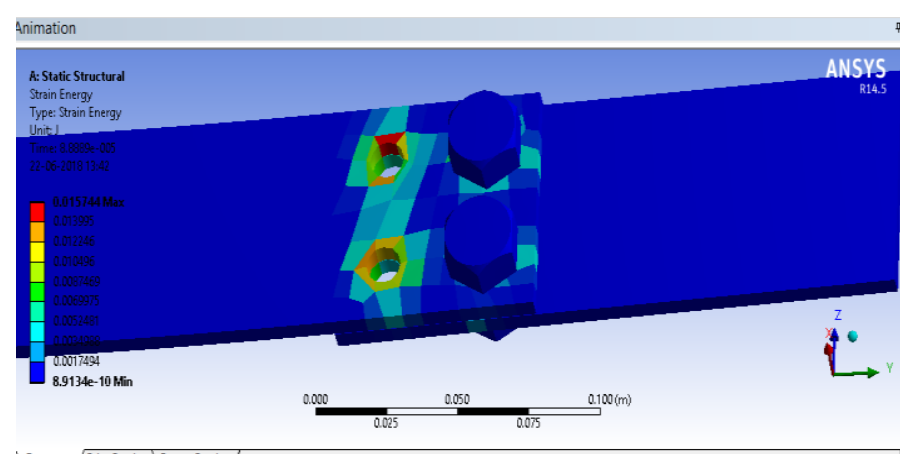

Fig 17: Strain energy of GFRP composite bolted joint.

\subsubsection{Stress analysis of Aluminum alloy, 6061, T6 bolted joint}

The maximum total deformation 3.7983e-004 is observed at the end where force is applied and the minimum force is observed at fixed end. The below figs shows the stress analysis results of Aluminum alloy, 6061, T6 bolted joint using ANSYS software.

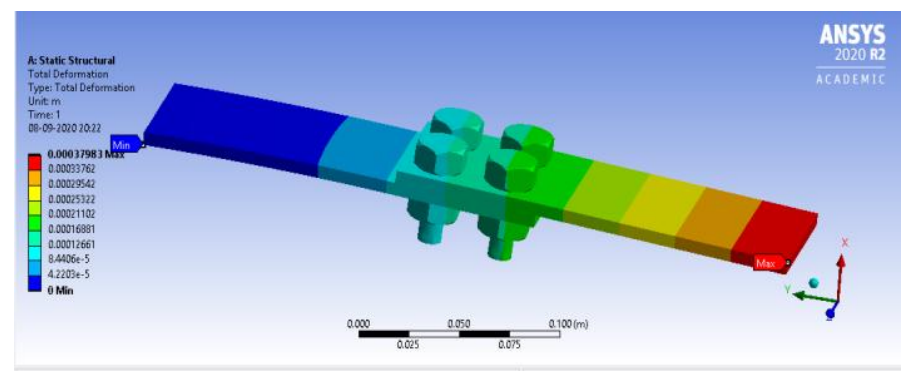

Fig 18: Total deformation of Aluminum alloy, 6061, T6 bolted joint.

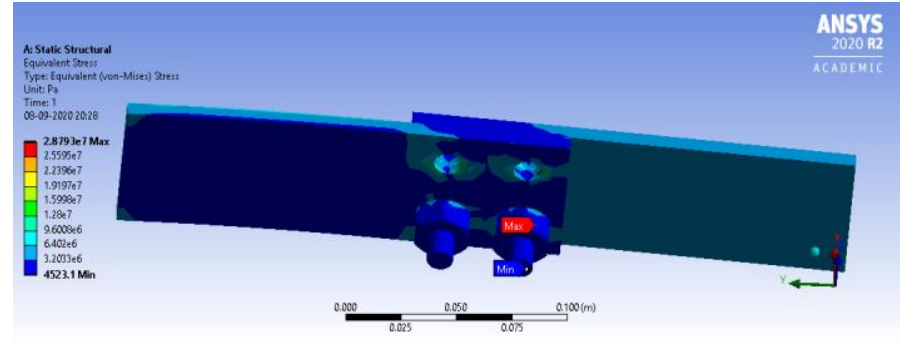

Fig 19: Von mises stress of Aluminum alloy, 6061, T6 bolted joint 


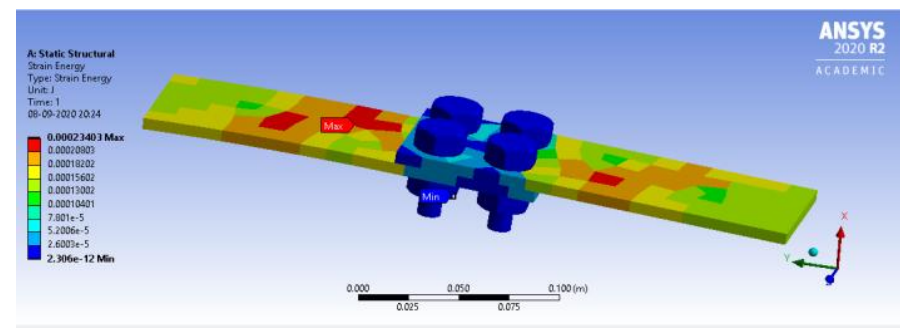

Fig 20: Strain energy of Aluminum alloy, 6061, T6 bolted joint.

Table 2. Comparison table of CFRP, GFRP composites and Aluminum alloy, 6061, T6 bolted joints:

\begin{tabular}{|c|c|c|c|}
\hline Material & Comment & Maximum & Minimum \\
\hline \multirow{8}{*}{ CFRP composite } & Vonmises stress & 60.109 & 0.00687 \\
\hline & $\mathrm{MPa}$ & $\mathrm{MPa}$ & $\mathrm{MPa}$ \\
\hline & Total deformation & 0.8542 & \\
\hline & $\mathrm{mm}$ & $\mathrm{mm}$ & 0 \\
\hline & & $3.0474 \mathrm{e}-8$ & \\
\hline & Strain energy & $\mathbf{J}$ & $7.2312 \mathrm{e}-8 \mathrm{~J}$ \\
\hline & Vonmises stress & 117.13 & $0.30077 \mathrm{MP}$ \\
\hline & $\mathrm{MPa}$ & $\mathrm{MPa}$ & $\mathrm{a}$ \\
\hline \multirow{5}{*}{ GFRP composite } & Total deformation & 0.36782 & \\
\hline & $\mathrm{mm}$ & $\mathrm{mm}$ & 0 \\
\hline & & $1.5744 \mathrm{e}-$ & $8.9259 \mathrm{e}-010$ \\
\hline & Strain energy & $002 \mathrm{~J}$ & $\mathrm{~J}$ \\
\hline & $\begin{array}{l}\text { Vonmises stress } \\
\mathrm{MPa}\end{array}$ & $\begin{array}{l}28.793 \\
\mathrm{MPa}\end{array}$ & $\begin{array}{l}0.0045231 \\
\mathrm{MPa}\end{array}$ \\
\hline \multirow[t]{2}{*}{ T6 } & $\begin{array}{l}\text { Total deformation } \\
\mathrm{mm}\end{array}$ & 0.37983 & 0 \\
\hline & Strain energy & $\begin{array}{l}2.3403 \mathrm{e}- \\
004 \mathrm{~J}\end{array}$ & J $2.306 \mathrm{e}-012$ \\
\hline
\end{tabular}

\section{Conclusion}

From structural analysis, the maximum stress is more in carbon fibre composite bolted joint when compared to GFRP and Aluminum alloy, 6061, T6.The deformation of CFRP material is more comparing to GFRP and Aluminum alloy, 6061, T6. The maximum strain is more in CFRP compare to GFRP and Aluminum alloy, 6061, T6. When compared with corresponding allowable strengths and deformation, the differences of these values is considerably more than GFRP and Aluminum alloy, 6061, T6 material hence it can be concluded that CFRP has high strength and efficient material.

\section{References}

Jauhari, Nitin, Raghvendra Mishra, and Harischandra Thakur. "Stress analysis in FRP composites." Perspectives in Science8 (2016): 50-52.

Gamdani, Farid, RachidBoukhili, and Aurelian Vadean. "Tensile strength of open-hole, pin-loaded and multibolted single-lap joints in woven composite plates." Materials \& Design 88 (2015): 702-712.

Coelho, Ana M. Girão, and J. Toby Mottram. "A review of the behaviour and analysis of bolted connections and joints in pultruded fibre reinforced polymers." Materials \& Design 74 (2015): 86-107.

Mandal, Bibekananda, and AnupamChakrabarti. "A simple homogenization scheme for 3D finite element analysis of composite bolted joints." Composite Structures 120 (2015): 1-9.

Wang, Zhi-Yu, Ning Zhang, and Qing-Yuan Wang. "Tensile behaviour of open-hole and bolted steel plates reinforced by CFRP strips." Composites Part B: Engineering 100 (2016): 101-113.

Rietz, Andreas. "Failure of bolt connection in fiber reinforced plastic component exposed to bending torque." Engineering Failure Analysis 84 (2018): 109-120.

Sonnenschein, Robert, Katarina Gajdosova, and Ivan Holly. "FRP Composites and their Using in the Construction of Bridges." Procedia Engineering 161 (2016): 477-482. 
Giannopoulos, Ioannis K., Damian Doroni-Dawes, Kyriakos I. Kourousis, and Mehdi Yasaee. "Effects of bolt torque tightening on the strength and fatigue life of airframe FRP laminate bolted joints." Composites Part B: Engineering(2017).

Bodjona, Kobyé, KarthikRaju, Gyu-Hyeong Lim, and Larry Lessard. "Load sharing in single-lap bonded/bolted composite joints. Part I: Model development and validation." Composite Structures 129 (2015): 268-275.

Zhao, Libin, AnXin, Fengrui Liu, Jianyu Zhang, and Ning Hu. "Secondary bending effects in progressively damaged single-lap, single-bolt composite joints." Results in Physics 6 (2016): 704-711. 